\title{
Bending Properties of 3D I-Shaped Woven Composites
}

\author{
Lihua Lyu*, Jingjing Wang, Yaoli Huang, Yongfang Qian, Fang Ye* \\ School of textile and material engineering, Dalian Polytechnic University, Dalian 116034, China
}

Corresponding Author: Lihua Lyu*, E-mail:lvlh@ dlpu.edu.cn.

\begin{abstract}
This paper dealt with the bending properties of 3D (three-dimensional) I-shaped woven composites with basalt fiber filaments tows and epoxy vinyl resin. The 3D I-shaped woven fabrics with three different heights were woven on ordinary loom by reasonable design with low cost. The 3D I-shaped woven composites were fabricated by VARTM(vacuum assisted resin transfer molding) process. The bending tests were conducted on a microcomputer control universal testing machine (TH-8102S). The load-displacement and energy-displacement scatter plots were obtained from experimental tests. The results showed that the polynomial fitting formula were obtained by the calculation of least square method in the software of origin 8.0. Through the analysis of the mathematical equation and correlation coefficient of load-displacement and energy-displacement relationship.it was seen that the fitting effect of the curve was very good.The mathematical equation of this method can be used to simplify the calculation of load, energy from displacement.
\end{abstract}

\author{
ARTICLE HISTORY \\ Received: 28.05.2019 \\ Accepted: 16.12.2019
}

\section{KEYWORDS}

3D woven fabric, I-shaped composites, Mathematical equation, Bending properties

\section{INTRODUCTION}

I-shaped structure of cast-in-situ concrete structure occupies a large proportion in bridge construction. Although the well-designed and well-maintained concrete structure can withstand various loads during many years of operation, due to the role of heavy vehicles and the erosion of the environment, the concrete bridge deck needs frequent maintenance, and still need to be renovated and replaced. For these reasons, 3D (three-dimensional) I-shaped woven composites have been used to overcome these difficulties due to their excellent mechanical properties [1].

3D I-shaped textile structural composites were fabricated with 3D I-shaped textile fabrics used as reinforced phase and resin used as matrix phase. Most ordinary I-shaped composites were pressed with plate material, and the processing method was simple, but the integrity of the ordinary I-shaped composites is poor and it is easy to crack [2]. Compared with ordinary fabrics, the 3D woven fabric has good integrity and many advantages like larger thickness, rigidity and light weight [3]. So 3D woven technique is superior in manufacturing the I-shaped preform. 3D woven composite has gained extensive attention for its high impact resistance and damage tolerance, low delamination and structural integrity. Muhammad [4] studied the peel strength of T-shaped and $\mathrm{H}$-shaped structures, and found that the mechanical properties of $\mathrm{T}$-shaped and $\mathrm{H}$-shaped interlocking structures are better than P-shaped and laminated structures compared with laminated structures. In weaving and designing, the 3D tubular woven fabric and other 3D woven fabric researched by our group also provide the basis for weaving the 3D I-shaped woven fabric of this paper [5].

I-shaped preform is a common structure used in engineering application like supporting structures on aircraft wings and ship decks. In the fabrication and the mechanical properties of 3D I-shaped composites, the mechanical behaviors of the I-shaped composites have been investigated extensively [6]. Zagon [7] studied the shear behavior of fiber reinforced I-shaped composites. A laminated composite beam with reduced proportions is proposed, but the wing of the I-shaped composite is a foam

To cite this article: Lyu L., Wang J., Huang Y., Qian Y., Ye F. 2020. Bending Properties of 3D I-Shaped Woven Composites. Tekstil ve Konfeksiyon, 30(1), pp:35-41. 
sandwich composite [8]. Zhou et al [9] studied the impact mechanical properties of 3D braided composite by setting three kinds of gas pressure. The results showed that the load, displacement and energy absorption increased with the increase of the shock gas pressure. Zheng et al[10] analyzed the bending properties of braided I-shaped composite. The results showed that the change of braiding parameters had a great influence on the properties of braided I-shaped composite. Even though a lot of researches had been done on the I-shaped composite, however, the bending properties of 3D I-shaped woven composites have not been reported comprehensively so far.

In terms of raw material selection, nowadays carbon fiber, kevlar fiber and glass fiber are mostly used in the preparation of composite materials. However, compared with these fibers, basalt fiber has the characteristics of high strength, high modulus, high temperature resistance, and compressive strength and shear strength, especially good environmental protection, and it can be completely biodegradable [11]. Therefore, basalt fiber is chosen as the raw material of 3D I-shaped woven composites. Many studies on basalt fiber reinforced composites have been done before [12]. But few studies have been done on 3D Ishaped woven composites with basalt fibers. The paper studied the bending properties of 3D I-Shaped woven composites with basalt fibers.

\section{MATERIAL AND METHOD}

\subsection{Material}

800tex basalt fiber filaments tows from Zhejiang Shijin Basalt Fiber Co., Ltd, (Zhejiang, China) were chosen as weft and warp yarns. Epoxy vinyl resin (V-118) from Wuxi Qianguang Chemical Co., Ltd, (Wuxi, China) was used as matrix. Loom in the lab (SGA 598) from Tongyuan Textile Machinery Co., Ltd, (Jiangyin, China) was used for weaving samples; VARTM molding system was used for molding; universal system prototype (QG-5A) from Kaya Industrial Co., Ltd, (Shanghai, China) was used for cutting samples, and universal testing machine (TH-8102S) from Suzhou Tuobo Machinery Equipment Co., Ltd (Suzhou, China) was used for testing, muffle furnace (SRJX-4-13A) from Zhejiang Xinnuo Instrument Co., Ltd (Shaoxing, China) was used for testing fiber volume fraction.

\subsection{Fabrication of 3D I-shaped Woven Composites}

Most of the 3D woven fabrics are designed by the common design method, that is, to directly design the warp section of the fabric, and then draw the pattern map according to the warp section. The thickness of the fabric designed by this method will be limited by the number of heald frames. Therefore, in the design process, in order to make the beam height of 3D I-shaped woven fabric not affected by the number of heald frames of loom, the method of multiple pattern board weaving is used for design and weaving, that is, flattening reduction method [13]. The specific weaving sketch of 3D I-shaped woven fabric was shown in the Figure 1. From Figure 1, it can be seen that the shape structure of $\mathrm{A} 1$ and $\mathrm{A} 3$ were same, so the same weaving structure was assigned to A1 and A3, therefore the same warp structural drawings and chain drafts utilized in this paper were to weave the structure of $\mathrm{A} 1$ and $\mathrm{A} 3$. The shape structure of $\mathrm{A} 2$ was different from $\mathrm{A} 1$ and $\mathrm{A} 3$, so using different warp structural drawings and chain drafts in this paper was manufactured the structure of A2. At the same time, the size of A1 was equal to A3, the size of A2 was designed according to requirements. In this paper the lengths of A2 was set to $20 \mathrm{~mm}, 40 \mathrm{~mm}$, and $60 \mathrm{~mm}$ respectively.

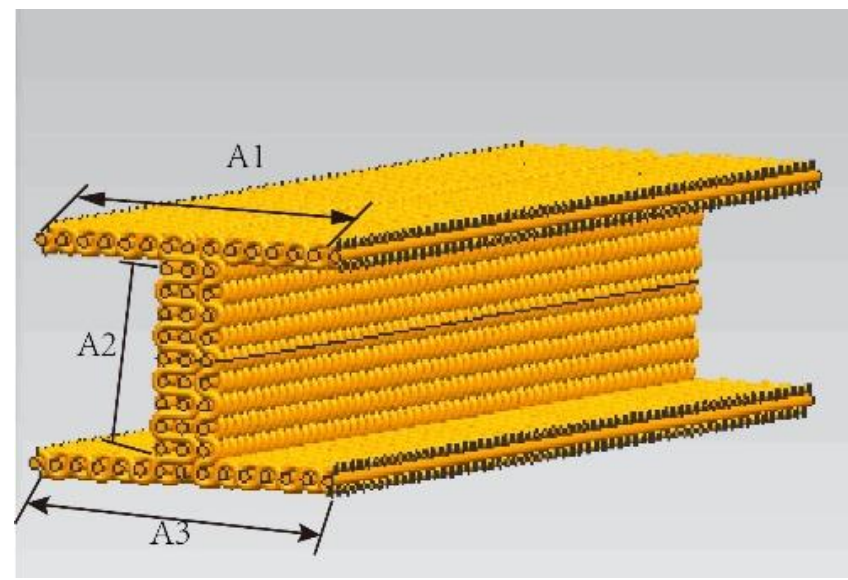

Figure 1. Specific weaving sketch of 3-D I-shaped woven fabric

3D I-shaped woven fabric belongs to multiple layers binding structure. Since the height of 3D I-shaped woven fabrics is determined by the weaving length of the $\mathrm{A} 2$, so the warp structural drawings and chain drafts were all same, just changing the weaving length of A2. The warp structural drawings of 3D Ishaped woven fabrics with three different heights are shown in Figure 2, as seen in Figure 2, (a) was warp structural drawings of A2, (b)was warp structural drawings of A1 and A3. According to the warp structure drawing, the chain draft of 3D I-shaped woven fabric with three different heights was drawn, as shown in Figure 3. As shown in Figure 3, (a)was the chain draft of A2, and (b) was the chain draft of $\mathrm{A} 1$ or $\mathrm{A} 3$.
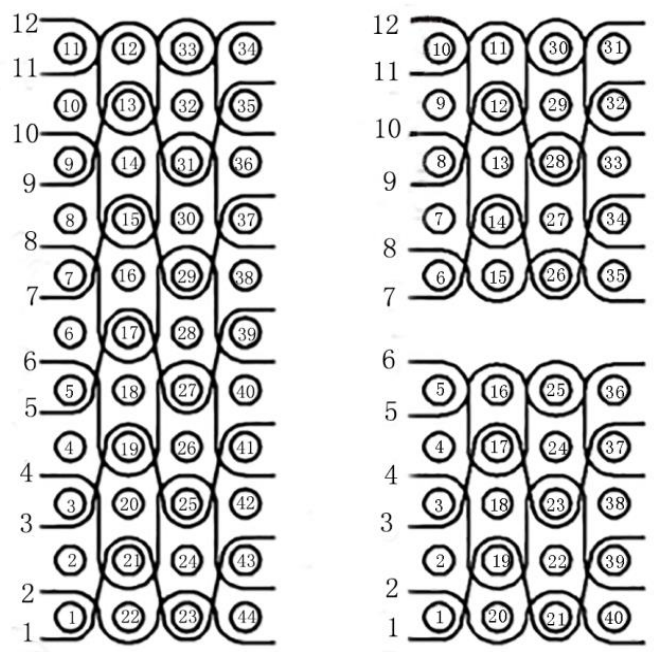

(a) Warp structural drawings of A2 (b) Warp structural drawings of A1 or A3

Figure 2. Warp structural drawings of 3D I-shaped woven fabrics with three different heights Note: The line was warp yarn and the circle was weft yarn 

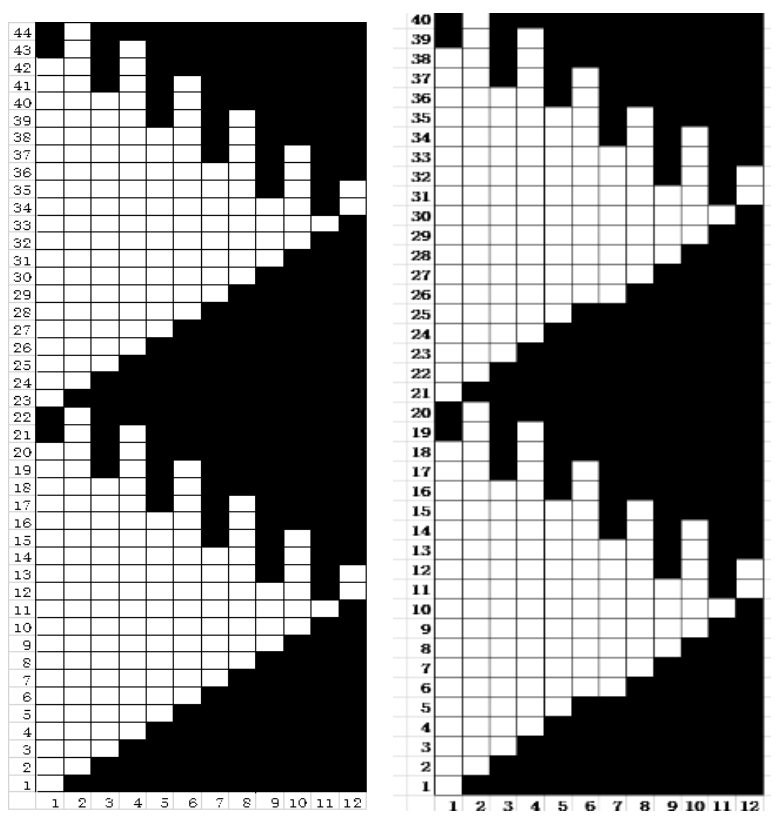

(a) Chain drafts of A2 (b) Chain drafts of A1 or A3

Figure 3. Chain drafts of 3D I-shaped woven fabrics with three different heights

Note: The black rectangles are warp interlacing point and the white rectangles are weft interlacing point, the numbers in vertical directions are weft numbers and numbers in horizontal directions are warp numbers.

The weaving parameters of 3D I-shaped woven fabrics were shown in Table. 1 The following are loom parameters for loom.

(1) width: 20 inches

(2) color selection: Manual

(3) number of heald frames: 16 pages; (standard configuration)

(4) coiling: manual or automatic;

(5) beating up device: manual;

(6) heald lifting frame: computer PLC control, pneumatic opening;

(8) power supply: rated power supply $220 \mathrm{~V}$, frequency $50 \mathrm{~Hz}$;

(9) overall dimension $(\mathrm{mm}): 1300 \times 980 \times 1510$; weight: $180 \mathrm{~kg}$; power: $1 \mathrm{KW}$

In order to produce the same heights of three different 3D Ishaped woven composites, the weaving parameters were all same except the heights of A2. For the same thickness, the bending properties, energy absorption properties and fiber volume fraction of different heights could be compared.

The 3D I-shaped woven composites were manufactured by VARTM process. And, the role of its principle and structure of each part could be seen in literatures[14]. The proportion of Epoxy vinyl resin, curing agent and accelerating agent was 400:5:5. In order to decrease the porosity in composite, the vacuum pressure in the bag was about $0.1 \mathrm{MPa}$ before resin injection. The epoxy vinyl resin was injected into the preform by VARTM technique. The curing condition included normal temperature(about 20 degrees Celsius) for $3 \mathrm{~h}$, then $80^{\circ} \mathrm{C}$ for $8 \mathrm{~h}$. As shown in Figure.4, the 3D I-shaped woven composites were cut into the testing length of 120 $\mathrm{mm}$. The thickness of the flanges was $30 \mathrm{~mm}$, and the heights of 3D I-shaped woven composites were $20 \mathrm{~mm}, 40$ $\mathrm{mm}, 60 \mathrm{~mm}$ respectively, which could be compared.

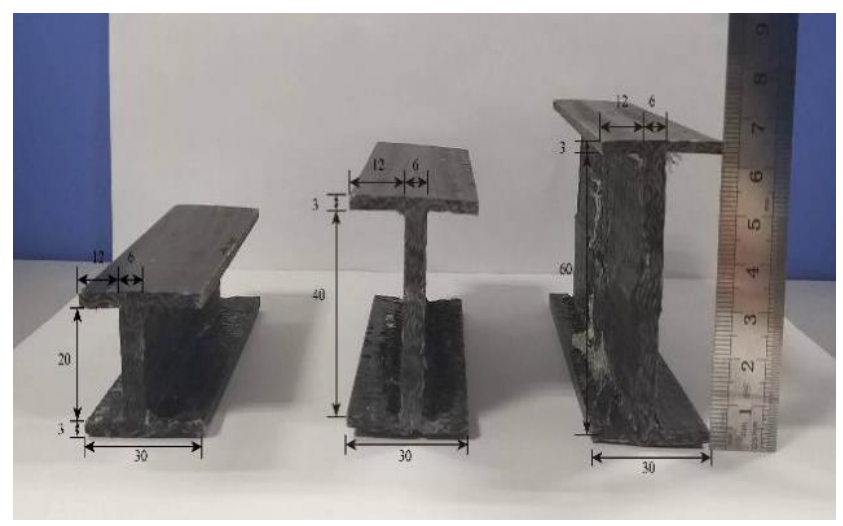

Figure 4. 3D I-shaped woven composites with three different heights Note: The unit of the dimensions is mm indicated in this figure.

\subsection{Characterization of 3D I-shaped Woven Composites}

The test was conducted using ISO 178:2001, and using a computer controlled universal testing machine (TH-8102S). The testing speed was $10 \mathrm{~mm} / \mathrm{min}$.

In this paper the energy absorption properties were evaluated by Energy-displacement scatter plots which were obtained by integrating the area of the load-displacement scatter plots curves in origin 8.0.

Fiber volume fraction is the ratio of fiber volume divided by composite volume and depending on the density of the constituent materials in a 3D I-shaped woven composites

In this paper the fiber volume fraction of the 3D I-shaped woven composites were achieved by burning method in muffle furnace which can be referred to the well-known standard ASTM D3171.

The fiber volume fraction is calculated by using the following formulas.

$V_{\text {Resin }}=\frac{\left(W_{1}-W_{2}\right)}{\delta_{\text {Resin }}}$

$V_{1}=\frac{V_{R e s i n}}{V} \times 100$

$V_{2}=\left(1-V_{1}\right) \times 100$

$\mathrm{V}$ is the total volume of the sample, $\delta_{\text {Resin }}$ is the resin density (the data provided by the supplier is $1.7 \mathrm{~g} / \mathrm{cm}^{3}$ ), $\mathrm{V}_{\text {Resin }}$ is the volume of resin, $\mathrm{W}_{1}$ is the weight of sample before burning, $\mathrm{W}_{2}$ is the weight of sample after burning, $\mathrm{V}_{1}$ is the resin volume fraction, and $\mathrm{V}_{2}$ is the fiber volume fraction.

Therefore, the experimental data obtained from the burning method in this paper were shown in Table 2. 
Table 1. Weaving Parameters of 3D I-shaped Woven Fabrics

\begin{tabular}{cccccc}
\hline \multirow{2}{*}{$\begin{array}{c}\text { Heights } \\
\text { /mm }\end{array}$} & Linear density/tex & \multicolumn{2}{c}{ Layer number of yarns } & \multicolumn{2}{c}{ Weaving density /root /10cm } \\
\cline { 2 - 6 } & Warp/weft yarns & $\mathbf{A 1 , A 3}$ & $\mathbf{A 2}$ & Warp density & Weft density \\
\hline $20 / 40 / 60$ & 800 & 5 & 11 & 480 & 1180 \\
\hline
\end{tabular}

Table 2. Fiber volume fraction of 3D I-shaped Woven Composites

\begin{tabular}{llllll}
\hline Heights/mm & $\mathbf{V}_{\mathbf{c m}} \mathbf{\mathbf { m } ^ { 3 }}$ & $\mathbf{W}_{\mathbf{1}} / \mathbf{g}$ & $\mathbf{W}_{\mathbf{2}} / \mathbf{g}$ & $\mathbf{V}_{\mathbf{1}} / \mathbf{\%}$ & $\mathbf{V}_{\mathbf{2}} / \mathbf{\%}$ \\
\hline 20 & 2.880 & 5.328 & 3.081 & 41.8 & 58.2 \\
40 & 4.488 & 8.097 & 4.677 & 44.8 & 55.2 \\
60 & 4.968 & 9.433 & 5.515 & 46.4 & 53.6 \\
\hline
\end{tabular}

\subsection{Origin 8.0 Numerical Fitting}

Although the testing process of bending test was relatively simple, it had large number of data to be measured in the experiment. The best method was the least squares method. Its advantage was that it accurately fit the curve linearly or non-linearly, but it had large amount of computation and complexity, and it was difficult to realize the artificial calculation through numerous formulas. Origin 8.0 software just used the least squares method to fit the data non-linearly according to load-displacement and energy-displacement scatter plots, which had been used by many scholars.

\section{RESULTS AND DISCUSSION}

This research investigated the bending properties of 3D Ishaped woven composites. First, 3D I-shaped woven fabrics with three different heights were woven on ordinary loom by reasonable design with low cost. Then 800tex basalt filaments were used as weft and warp yarns. And the 3D Ishaped woven composites were fabricated by VARTM(vacuum assisted resin transfer molding)process. The bending test was carried out on the microcomputer control universal testing machine (TH-8102S). The loaddisplacement and energy-displacement scatter plots were obtained from experimental test. Finally the software of Origin 8.0 was used to fit the load-displacement and energy-displacement scatter plots. The results showed that the polynomial fitting formulas were obtained by the calculation of least square method in origin 8.0.

\subsection{Analysis of Load-displacement Curves}

The bending properties of 3D I-shaped woven composites under three-point bending test were evaluated by loaddisplacement scatter plots and energy-displacement scatter plots. By observing the load-displacement scatter plot, the method of 8-orders polynomial fitting was finally adopted. The load-displacement scatter plots were obtained from experimental data, and then fitted by least square method in software origin 8.0. The load-displacement scatter plots and fitting curves of 3D I-shaped woven composites with three different heights were shown in Figure.5.

After that the polynomial fitting formula could be obtained by the calculation of least square method in origin 8.0. The mathematical equation of fitting curve and correlation coefficient of load-displacement relationship were shown in Table.3. From the correlation coefficient in Table 3, it could be seen that the fitting effect of the curve was very good. The fitting results depended on the correlation coefficient " $R$ ". The value range of " $R$ " was $0<R \leq 1$, and the value was to 1 and the consistent was good of the curve and formula. This mathematical equation of fitting curve could be used to simplify calculation of load from displacement.

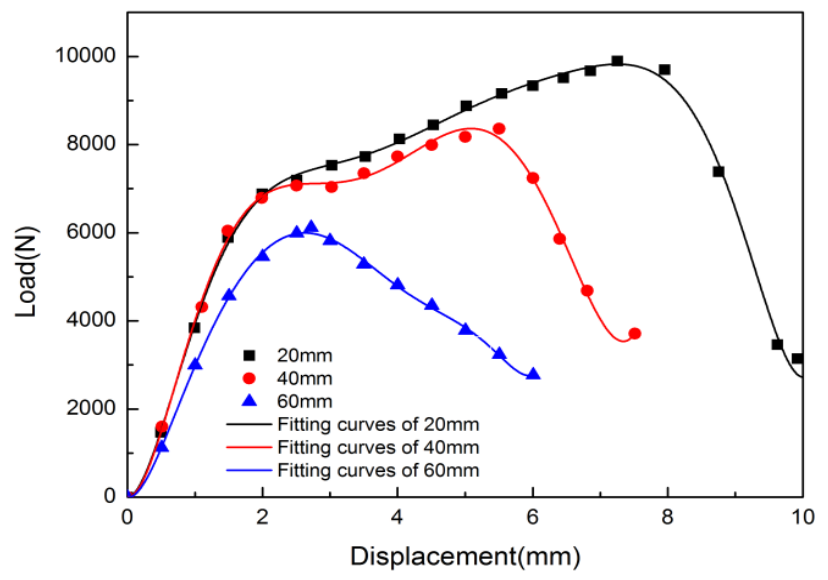

Figure 5. Load-displacement scatter plots and fitting curves of 3D Ishaped woven composites with three different heights

It could be seen from Figure. 5 that the maximum load of the composites decreased gradually with the increase of the height of 3D I-shaped woven composites. This was mainly because the center of gravity of the composites increased with the increase of the heights, and the ability endure the damage decreased in the bending process. And analysis of Figure.5 showed that all three fitting curves could be divided into three stages. At the beginning, the fitting curves were almost linear, this indicated that bonding situation was good between resin and fiber. So, the composites exhibited linearly elastic performance. Secondly, the curves no longer presented straight lines and the slope of curves decreased with the increase of displacement. This was because the contact surface area increased with the increase of displacement between the samples and indenter, and the resin began to destroy. Finally, at the peak, the curve began to decline rapidly and the composites began to have shear destruction. 
Table 3. Mathematical Equation of Fitting Curve and Correlation Coefficient of load-displacement relationship

\begin{tabular}{ccc}
\hline Heights/mm & Mathematical Model Equation of Fitting Curve & $\begin{array}{c}\text { Correlation } \\
\text { Coefficient }\end{array}$ \\
\hline \multirow{2}{*}{20} & $\mathrm{Y}=-15.434+263.249 \mathrm{x}+8522.060 \mathrm{x}^{2}-6912.590 \mathrm{x}^{3}+2532.792 \mathrm{x}^{4}-507.943 \mathrm{x}^{5}+57.632 \mathrm{x}^{6}-$ & 0.99676 \\
& $3.474 \mathrm{x}^{7}+0.086 \mathrm{x}^{8}$ & 0.99510 \\
40 & $\mathrm{Y}=6.070-178.334 \mathrm{x}+9402.190 \mathrm{x}^{2}-7280.569 \mathrm{x}^{3}+2455.145 \mathrm{x}^{4}-434.173 \mathrm{x}^{5}+42.215 \mathrm{x}^{6}-$ & 0.99722 \\
& $2.234 \mathrm{x}^{7}+0.055 \mathrm{x}^{8}$ & \\
60 & $\mathrm{Y}=-2.005-165.9005 \mathrm{x}+7612.0445 \mathrm{x}^{2}-7157.535 \mathrm{x}^{3}+3674.481 \mathrm{x}^{4}-$ & 0.9972 \\
\hline
\end{tabular}

This also could be seen from the load-displacement curves that with the increase of displacement, the load reached the maximum, the fracture of composites became more severe. It showed that the curves were fluctuant and the peak load decreased during the three different heights and after damage initiation, the composites rigidity was degraded gradually according to the specified damage evolution law. This was because that the uninterrupted fiber fracture and resin rupture emerged in the process of bending. And the bending damage was mainly focused on the junction between the top flange and the web.

It also could be seen from Figure. 6 that the bending properties of the 3D I-shaped woven composites with 20 $\mathrm{mm}$ was the best, because the composite with the heights of $20 \mathrm{~mm}$ had bigger rigidity and bigger maximum bending load comparing to the composites with the heights of $40 \mathrm{~mm}$ and $60 \mathrm{~mm}$. And the bending properties of the 3D I-shaped woven composites with the height of $60 \mathrm{~mm}$ was the worst, and the bending properties of the 3D I-shaped woven composites with the height of $40 \mathrm{~mm}$ was between the both.

\subsection{Analysis of Energy-displacement Curves}

The energy absorption behavior of textile composites has been an attractive research topic in recent years, so in this paper the energy-displacement scatter plots were obtained from experimental data, and by observing the energydisplacement scatter plot, the method of 3-orders polynomial fitting was finally adopted, then fit by least square method in software origin 8.0. The energy-displacement scatter plots and fitting curves of 3D I-shaped woven composites with three different heights were shown in Figure.6.

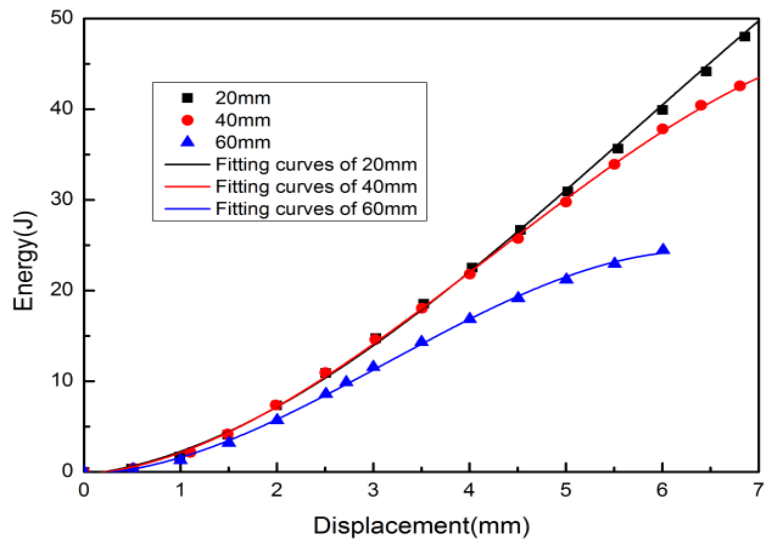

Figure 6. Energy-displacement scatter plots and fitting curves of 3D Ishaped woven composites with three different heights

And the mathematical model equation of fitting curve and correlation coefficient of load-displacement relationship were shown in Table.4. This mathematical equation of fitting curve could be used to simplify calculation of energy from displacement. From the correlation coefficient in Table 3, it was seen that the fitting effect of this curve was good. From Figure 6, the energy absorption value increased with the decrease of the height of 3D I-shaped woven composites, the bending properties and energy absorption properties of 3D I-shaped woven composites were in proportional to each other. This conclusion was consistent with the previous studying results in this aspect by other scholars[15]

Energy absorption is also an important index of cushioning performance and impact resistance of composites in the bending process. So the cushioning performance and impact resistance of 3D I-shaped woven composites increased with the decrease of height. This was mainly because the center gravity of composites increased with the increase of height, there was a three-point bending failure mode in the composites, which was compression failure on the upper surface, tension failure on the lower surface and shear failure on the web surface. Therefore, the energy absorption mechanism was the expansion of cracks in the 3D I-shaped woven composites and the increase of the compression area of the composites.

\subsection{Analysis of Fiber Volume Fraction}

From Table 2, it was seen that the fiber volume fraction of the 3D I-shaped woven composites with the height of $20 \mathrm{~mm}, 40$ $\mathrm{mm}, 60 \mathrm{~mm}$ were $58.2 \%, 55.2 \%, 53.6 \%$ respectively. It showed that the fiber volume fraction decreased with the increase of the heights of 3D I-shaped woven composites. Combining with Figure 5 and Figure 6, the results showed that the increasing fiber volume fraction improved the bending properties of the 3D I-shaped woven composites. This conclusion was consistent with the previous studying results in this aspect by other scholars [16-17].

\subsection{Analysis of Failure Mode and Failure Mechanism}

The trend of 3D I-shaped woven composites with different heights is similar and the failure mode and failure mechanism are the same. Therefore, the failure mode and failure mechanism of the 3D I-shaped woven composites with the height of $20 \mathrm{~mm}$ were explained as an example.

The overall and partial enlargement photographs of 3D Ishaped woven composites with the height of $20 \mathrm{~mm}$ were shown in Figure. 7. As seen in Figure 7, (a) was the overall and partial enlargement failure modes on the top flange of the composites, (b) was the overall and partial enlargement failure modes of the bottom flange of the composites, and (c) was the overall and partial enlargement failure modes on the web of the 3D I-shaped woven composite. 
Table.4 Mathematical Equation of Fitting Curve and Correlation Coefficient of energy-displacement relationship

\begin{tabular}{ccc}
\hline Heights/mm & Mathematical Equation of Fitting Curve & Correlation Coefficient \\
\hline 20 & $\mathrm{Y}=-297.397+1222.219 \mathrm{x}+1424.755 \mathrm{x}^{2}-82.105 \mathrm{x}^{3}$ & 0.99946 \\
40 & $\mathrm{Y}=249.761+785.854 \mathrm{x}+1747.292 \mathrm{x}^{2}-138.098 \mathrm{x}^{3}$ & 0.99964 \\
60 & $\mathrm{Y}=-242.158+302.282 \mathrm{x}+1725.884 \mathrm{x}^{2}-183.167 \mathrm{x}^{3}$ & 0.99897 \\
\hline
\end{tabular}

From Figure. 7, the bending failure modes showed that the 3D I-shaped woven composites was a typical bending failure modes with the compression failure in the top flange and tensile failure in the bottom, there was also shear failure in the web. Then, the bending failure modes of 3D Ishaped woven composite with $40 \mathrm{~mm}$ and 3D I-shaped woven composite with $60 \mathrm{~mm}$ were similar to 3D I-shaped woven composite with $20 \mathrm{~mm}$.

In the aspect of damage, at the beginning, the damage distribution was mainly focused on the point where the pressure head located and the two fixed edges. Subsequently, with the increase of displacement, the damage area increased gradually. The damage of the top flange and the bottom flange were both serious, and damage in the web was next to the flange, this was because the stress wave spread from the top flange to the web, and at the same time the force in the reinforcement inclined forward to the web. This was due to the complex weaving structure in the reinforcement, which had be explained in the part two of this paper.

With the increase of the height, the destruction of the composites was worse, but there was no lamination in the 3D I-shaped woven composites. It was clear that the 3D Ishaped woven composites had high delamination resistance. There were cracks appearing in the direction of the web in the 3D I-shaped woven composite, this was mainly caused by the low fracture toughness of epoxy resin.

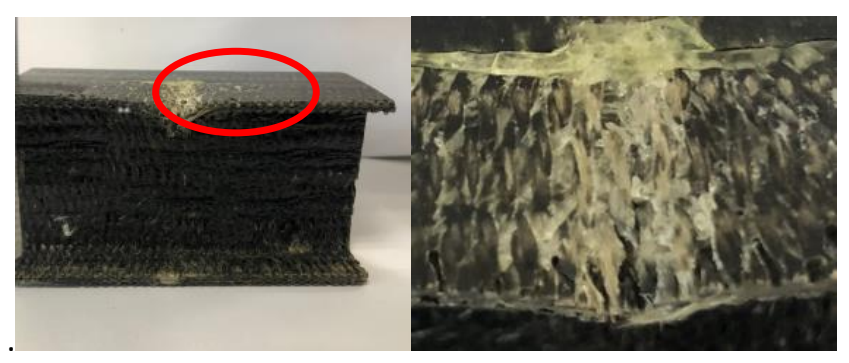

(a) The overall and partial enlargement failure modes on the top flange of the composites

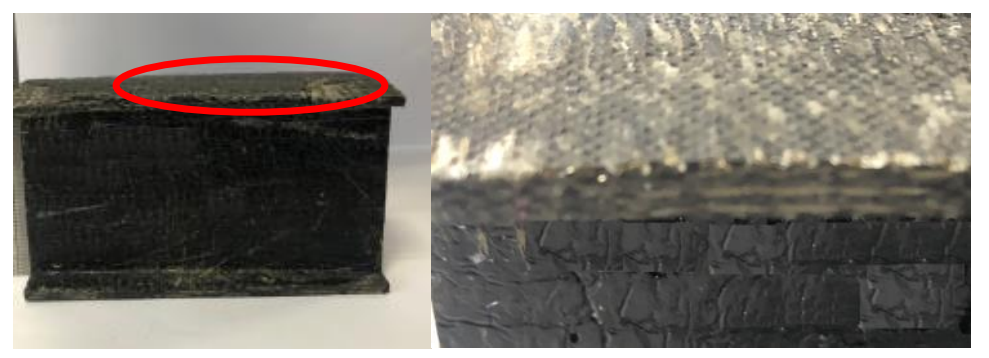

(b) The overall and partial enlargement failure modes of the bottom flange of the composites

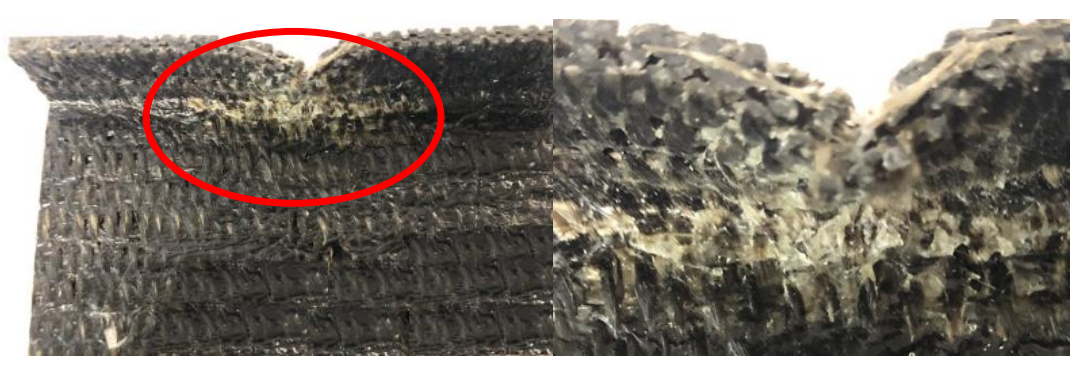

(c) The overall and partial enlargement failure modes on the web of the 3D I-shaped woven composite

Figure 7. Failure modes of overall and partial enlargement photographs of 3D I-shaped woven composites with the height of $20 \mathrm{~mm}$ 


\section{CONCLUSION}

From the results of this study, the following conclusions were drawn :

1. 3D I-shaped woven fabrics with three different heights were woven on ordinary loom by reasonable design with low cost processing.

2. The 3D I-shaped woven composite with $20 \mathrm{~mm}$ has the maximum load. The 3D I-shaped woven composite with 60 $\mathrm{mm}$ has the minimum load. The 3D I-shaped woven composite with $40 \mathrm{~mm}$ has the load between the two. The bending properties of 3D I-shaped woven composites increased with the decrease of height.

3. Through the analysis of origin 8.0 fitting results, it showed that the polynomial fitting formula could be obtained by the calculation of least square method in origin 8.0. And it could be seen that the fitting effect of the curve was better. This mathematical equation of fitting curve

\section{REFERENCES}

1. S. Y. Nayak. S. S. Heckadka, R. V. Sadanand. 2017. 2D woven/ 3D orthogonal Woven Non-crimp E-glass Fabric as Reinforcement in Epoxy Composites using Vacuum Assisted Resin Infusion Molding Journal of Engineering. Fibers \& Fabric 12(2),12-19.

2. Fu Y, Xiong J , Luo C. 2015. Static mechanical properties of hybrid RTM-made composite I- and П-beams under three-point flexure Chinese Journal of Aeronautics 28(3):903-913.

3. M. Gresil , M. N. Saleh, C. Souti. 2016. Transverse Crack Detection in 3D Angle Interlock Glass Fibre Composites Using Acoustic Emission Materials. 9(8):699-

4. U. Muhammad, N. Yasir, M. Mumtaz. 2015. Development and characterization of three-dimensional woven-shaped preforms and their associated composites, Journal of Reinforced Plastics Composite 34(24), 2018-2028.

5. X. F. Zhang, L. H. Lv, S. J. Yan. 2016. Design and weaving of Tshaped three-dimensional woven fabric with hole tube insertion, Shanghai Textile Science \& Technology 44(9), 14-15.

6. Z. B. He, L. T. Zhang, B. Chen. 2015. Failure behavior of 2D C/SiC Ibeam under bending load. Composite. Structure 132(15), 321-330.

7. Zagon R , Matthys S, Kiss Z .2016. Shear behaviour of SFR-UHPC Ishaped beams. Construction and Building Materials 124:258-268.

8. M. E. Asl, C. Niezrecki, J. Sherwood. 2017. Experimental and theoretical similitude analysis for flexural bending of scaled-down laminated I-beams, Composite. Structure. 176, 812-822.

9. Zhou H, Hu D, Zhang W, et al. The transverse impact responses of 3-D braided composite I-beam. Composites Part A: Applied Science and Manufacturing 94:158-169. could be used to simplify the relationship between load, energy and displacement.

4. The 3D I-shaped woven composites has excellent mechanical properties. In the test process, the composites showed good interlaminar shear strength, no delamination and splitting phenomenon. And, the height of the 3D Ishaped woven fabrics utilized as the reinforced composites were different, and the bending properties of composite made of 3D I-shaped woven fabrics also showed a big difference, but all of them had same failure modes and failure mechanism.

\section{Acknowledgement}

This research was funded by the National Science Foundation of Liaoning Province (2019-MS-017) and Technological Innovation Team Project of Liaoning Province (LT2017017).

10. C. H. Zheng, G. M. Zhou, W. F. Dong.2014. Study on bending properties of three-dimensional five-directional braided I-shaped composites structure. Fiber. Glass 2014(5), 39-45.

11. V. D. Nguyen, J. X. Hao, W. H. Wang. 2018. Ultraviolet Weathering Performance of High-Density Polyethylene/Wood-Flour Composites with a Basalt-Fiber-Included Shell, Polymer 10,831.

12. L. Z. Zhou, Y. Zheng, S. S. Taylor. 2018. Finite-Element Investigation of the Structural Behavior of Basalt Fiber Reinforced Polymer (BFRP)- Reinforced Self-Compacting Concrete (SCC) Decks Slabs in Thompson Bridge, Polymer 10(6),678.

13. X. Gao, Q. L. Hu, Y. X. Ma. 2017. Bending properties comparison of thick-section carbon fiber composites based on different threedimensional woven structures, Journal of Textile Research 38(9), 6571 .

14. M. Schenke, W. Ehlers. 2016. Numerical investigation of vacuumassisted resin transfer moulding (VARTM) within deformable fibre fabrics. PAMM 16(1), 479-480.

15. X. K. Liu, B. B. Yang, L. S. Lu. 2018. A Thermoplastic Multilayered Carbon-Fabric/Polycarbonate Laminate Prepared by a Two-Step HotPress Technique. Polymer 10(7), 1-17.

16. X. P. Wu, J. J. Dai, Y. Z. Tang. 2016. Study on epoxy/basalt fiber composites fabricated via compression molding process. Engineering Plastics. Application 2016, 44(1), 16-21.

17. M. Sussmann, M. Amirkhosravi, M. Pishvar. 2018. Fabrication of high quality, large wet lay-up/vacuum bag laminates by sliding a magnetic tool. Polymer 10, 1-17 